\title{
A TEORIA CRÍTICA DE KARL MARX NAS PERSPECTIVAS DE THEODOR ADORNO E ENRIQUE DUSSEL ${ }^{1}$
}

Rosalvo Schütz ${ }^{2}$

\begin{abstract}
Resumo:
Mesmo tendo sido a teoria de Hegel muito fecunda para Marx, o caráter crítico do pensamento de Marx se deve mais a sua capacidade de pensar à contrapelo de Hegel. Marx não se contenta em descrever certa realidade a partir de um princípio: busca evidenciar as possibilidades objetivas existentes, mas bloqueadas e não tematizáveis a partir de uma determinada totalidade. Tanto Adorno quanto Dussel apontam para esta dimensão do pensamento de Marx como fundadora do seu caráter crítico: pensar desde a exterioridade, desde o não-idêntico. Exemplarmente isto será demonstrado na função que o trabalho vivo e produtividade viva tem para Marx.
\end{abstract}

Palavras-chave: Totalidade. Não-idêntico. Exterioridade. Teoria Crítica.

\section{CRITICAL THEORY OF KARL MARX IN THE PROSPECTS OF THEODOR ADORNO AND ENRIQUE DUSSEL}

\begin{abstract}
:
Although Hegel's theory was very fertile for Marx, Marx's critical thought character is due to his ability to think opposing to Hegel. Marx thinks it is not enough to describe a certain reality from a principle. He searches for evidecing the existing objective possibilities and simultaneously blocked and not thematized from a determined totality. Both Adorno and Dussel point out this dimension by Marx as the founder of his critical character: think from the exteriority, the non-identical. Exemplarily, it will be demonstrated in the function that the alive work and productivity have in Marx's theory.
\end{abstract}

Keywords: Totality. Non-identical. Exteriority. Critical Theory.

\section{1- Introdução}

A teoria de Karl Marx é uma crítica em relação à sociedade capitalista: nisto concordam as mais diversas abordagens e interpretações quanto a esse autor. $\mathrm{O}$ que caracteriza sobremaneira o conjunto de suas obras é, fundamentalmente, o seu caráter crítico, como revela inclusive o subtítulo de sua principal obra: $O$ Capital: crítica da

1 Este texto é uma versão modificada e reduzida do capítulo de livro: O que faz da teoria de Karl Marx uma teoria crítica? Convergências entre Theodor Adorno e Enrique Dussel. In: Schütz, Rosalvo; Zimmermann, Rainer E. Crítica e Utopia: perspectivas brasileiras e Alemãs. Porto Alegre: Editora Sulina, 2012, p. 120-151.

2 Professor dos Cursos de Graduação e PPG em filosofia da UNIOESTE (Universidade Estadual do Oeste do Paraná). Bolsista de produtividade do CNPq. E-mail: rosalvoschutz@ hotmail.com 


\section{A TEORIA CRÍTICA DE KARL MARX NAS PERSPECTIVAS DE...}

Rosalvo Schütz

economia política. Como veremos, o caráter imanente de suas abordagens vem acrescido da crítica daquilo que é exposto, não permitindo que sua teoria se degrade em simples descrição e legitimação. Nossa tese é que este aspecto crítico é um indício de algo que não se deixa restringir à herança hegeliana.

Sabendo da fecunda e confessa influência da teoria de Hegel sobre Marx facilmente corremos o risco de supor que a crítica à sociedade capitalista desenvolvida, especialmente em $O$ Capital, teria se tornado possível pela apropriação desse poderoso instrumental que é a dialética hegeliana. Fazendo uso desse método herdado de Hegel, Marx teria superado não só os socialistas utópicos e o caráter não histórico de L. Feuerbach, mas, principalmente, superado as teorias da economia política da época, como a de A. Smith e D. Ricardo. Uma leitura apressada pode ainda levar a crer que a postura hegeliana the teria fornecido os instrumentos básicos para ultrapassar e desvendar o mundo das aparências dessa sociedade - com o que os economistas da época não teriam conseguido romper - desvendando, através do esforço de reconstrução teórica da realidade, a aparência da sociedade capitalista a explicitando sua essência, numa perspectiva hegeliana.

De fato, a importância da teoria e do método hegeliano é inquestionável para o desenvolvimento da teoria marxiana ${ }^{3}$. Muito facilmente, no entanto, pode-se concluir disso que o caráter crítico da teoria de Marx, comparado, por exemplo, aos teóricos da economia política da época, estaria justamente nessa postura dialética herdada de Hegel. De que através desse instrumental Marx teria conseguido evidenciar relações de dominação e de exploração que esses teóricos não conseguiram perceber por estarem apegados às aparências dessa sociedade. As teorias deles, então, teriam permanecido superficiais e equivocadas ou até mesmo erradas. Ao explicitar a essência da sociedade capitalista, num esforço teórico superior, Marx teria desmascarado os verdadeiros fundamentos ocultos: as artimanhas ideológicas com base nas quais se fundariam as

3 Quanto à observação de Marx de que seria preciso pôr Hegel de "cabeça para baixo" (Marx, 1988, p. 16), ou seja, de que seria preciso iniciar o processo de reconstrução da realidade a partir do material e não do espiritual, em nada modifica a intencionalidade principal dessa postura dialética: ir das aparências às essências, do abstrato ao concreto, de forma que essa inversão não implica automaticamente na criticidade da teoria deste em relação àquele.

\begin{tabular}{|l|l|l|l|l|}
\hline Q ovista Dialectus & Ano 5 & n. 12 & Janeiro - Julho 2018 & p. 439-461 \\
\hline
\end{tabular}




\section{A TEORIA CRÍTICA DE KARL MARX NAS PERSPECTIVAS DE...}

Rosalvo Schütz

pretensões de validade e legitimidade de uma sociedade baseada na desigualdade, na exploração e na opressão.

Certamente há um conteúdo de verdade por detrás dessa leitura das obras de Marx: não restam dúvidas de que a herança hegeliana fui fundamental principalmente para o fortalecimento do caráter dialético e imanente das suas obras. Há, no entanto, ao menos duas questões muito intrigantes que se impõem diante dessa leitura. A primeira diz respeito à diferença da teoria de Marx com a dos teóricos da economia política: chegariam eles a conclusões críticas semelhantes às de Marx caso estivessem de posse de um instrumental dialético hegeliano como foi o caso dele? Ou, em outras palavras, foi Marx apenas um economista melhorado conseguindo apontar as falhas e os equívocos desses teóricos, simplesmente por estar de posse desse poderoso instrumental chamado dialética hegeliana? Será que já não havia em Marx um pressuposto crítico anterior a qualquer pretensão descritiva, que lhe permitiu inclusive criticar o próprio Hegel? A segunda questão diz respeito à própria teoria hegeliana: ora, basta conhecer qualquer obra de Hegel em que ele se utiliza do método em que ultrapassando-superando (aufhebend) as aparências descreve os fundamentos e princípios essenciais de uma totalidade - como, por exemplo, a sua Filosofia do Direito -, para poder afirmar que sua teoria só com muita dificuldade pode ser considerada uma crítica da sociedade. Em Hegel os sacrifícios humanos e naturais decorrentes da lógica/totalidade em questão (no caso da Filosofia do Direito: o Estado de Direito moderno) aparecem antes como sendo um mal necessário em vista de um bem maior, os espinhos pelos quais se tem de passar para poder colher a rosa. A teoria de Hegel é, nesse sentido, antes uma justificação e legitimação da lógica existente do que uma crítica ${ }^{4}$. Por outro lado, basta ler algum texto de Marx ou apenas algumas páginas de $O$ Capital para ter a certeza de que neste caso se trata de uma teoria crítica da sociedade capitalista. Marx, portanto, parece ter buscado realizar algo inédito: expor a lógica imanente da sociedade capitalista e, simultaneamente, realizar uma crítica dela.

O que não quer dizer que não existem potenciais críticos inerentes à teoria deste e que, como o próprio Marx afirma, "em muito ultrapassam a própria intencionalidade deste autor". A este respeito veja-se, por exemplo, o texto de Flickinger (2004): "O potencial crítico da filosofia do direito".

\begin{tabular}{|l|l|l|l|l|}
\hline Q Poxista Dialectus & Ano 5 & n. 12 & Janeiro - Julho 2018 & p. 439-461 \\
\hline
\end{tabular}




\section{A TEORIA CRÍTICA DE KARL MARX NAS PERSPECTIVAS DE...}

Rosalvo Schütz

$\mathrm{Se}$, para Hegel, importava apenas descrever a realidade do ponto de vista racional, de maneira a aceitá-la somente na medida em que pudesse ser exposta de forma racional $^{5}$, o interesse de Marx não parece ter se limitado a essa intencionalidade: seu objetivo fundamental era a crítica. Marx não se satisfez com o princípio metodológico anunciado por Hegel de aceitar como real apenas o que poderia ser explicado a partir de um princípio racional. Em outras palavras, não aceitou reduzir o ser ao pensar e, assim, em mover-se apenas na totalidade constituída a partir de um determinado princípio. O autor parece ter se preocupado mais em denunciar as pretensões totalitárias de certos princípios abstratos, na medida em que os mesmos representam a pretensão de reduzir e explicar toda a realidade, do que simplesmente descrevê-los. Importava-se menos com a simples exposição de uma realidade baseada em um princípio (como, por exemplo, o princípio do (apital) do que em realizar a crítica desse princípio: uma intencionalidade com a qual Hegel não se ocupava ${ }^{6}$. Donde se pode concluir que, provavelmente, o caráter crítico da teoria de Marx não advém de sua herança hegeliana: a adesão à dialética hegeliana não foi suficiente para garantir o caráter crítico. A instrumentalização crítica do método hegeliano só parece ter se tornado possível por algo anterior a essa adesão. Afinal, há muitos leitores de Hegel, com capacidade cognitiva, legitimidade e produtividade teórica inquestionáveis, e que não se pretendem adeptos de uma teoria crítica da sociedade.

De fato, o caráter crítico da teoria de Marx não parece poder ser entendido a partir de sua herança hegeliana, nem tampouco na medida em que é compreendido como sendo um economista melhorado, por mais que esses aspectos tenham sido importantes para o desenvolvimento de sua teoria. Ambos foram apenas pontos de apoio, instrumentais importantes para o desenvolvimento do conjunto de sua obra. Como, então, entender sua postura crítica e, portanto, aquilo que faz de sua teoria uma teoria crítica? Talvez, portanto, seja interessante buscar compreender o que garantiu o caráter crítico da

5 Conforme o anúncio da convicção metodológica do próprio Hegel: "O que é racional, isto é efetivo; e o que é efetivo, isto é racional" (2010, p. 41).

6 O que fora anunciado pelo próprio Hegel, por exemplo, na introdução à Filosofia do Direito, ao referirse à filosofia enquanto coruja de Minerva, "que somente começa seu voo com a irrupção do crepúsculo" (2010, p. 44). Marx, por isso, nunca criticou Hegel por não ter descrito de forma adequada os princípios dessa realidade, mas, sim, pelo fato de não ter criticado essa realidade. Por isso Marx propõe o galo (que anuncia a chegada de um novo dia!) como mais uma figura representativa da filosofia.

\begin{tabular}{|l|l|l|l|l|}
\hline Q oxista Dialectus & Ano 5 & n. 12 & Janeiro - Julho 2018 & p. 439-461 \\
\hline
\end{tabular}


Rosalvo Schütz

sua teoria, ou seja, desde onde seus argumentos críticos se constituem e legitimam? ${ }^{7}$ Certo, de todo modo parece ser que, no caso da teoria Marx, a verdade não pode ser anunciada como um resultado puramente lógico, descritivo e a-histórico (mesmo que esta seja supostamente baseada na lógica da dialética hegeliana). Se fosse assim, sua teoria não poderia passar de uma simples descrição daquilo que se apresenta oficialmente como totalidade. Pode-se afirmar como veremos adiante, que a simples aceitação e repetição das teorias de Marx, como se fossem uma receita pronta para algo, significaria uma recaída no dogmatismo, inviabilizando a visualização das potencialidades emancipatórias objetivamente existente no presente histórico. A capacidade de elaboração e teorização de Marx diante da realidade - não caindo nem no utopismo abstrato nem na simples descrição da realidade a partir de um esquematismo prévio - parece nos autorizar a concluir que o caráter crítico de sua teoria pode ser definido antes como uma postura teórica frente à realidade histórica do que uma adesão a algum conteúdo fixo ou teses determinadas.

Posto este horizonte, nos próximos itens buscaremos dialogar com autores e temas que contribuam para o aprofundamento desta perspectiva que nos parece fecunda e produtiva.

\section{2- Em busca do caráter crítico da teoria de Karl Marx}

A diferenciação entre teoria tradicional e teoria crítica da sociedade, elaborada por Horkheimer (1975) em seu texto paradigmático certamente contribui muito para a investigação em torno do que seja o caráter crítico de uma teoria numa perspectiva social. A descrição dos traços fundamentais de uma teoria crítica, no entanto, pouco nos diz a respeito do que efetivamente faz com que alguém tenha ou desenvolva uma postura crítica da realidade, fato esse que antecede a própria definição do que seja teoria crítica. O que teria levado Marx a fazer uma apropriação crítica tanto dos socialistas utópicos quanto da teoria hegeliana, assim como das teorias da economia política de sua época?

7 Embora também seja importante ressaltar que para apropriar-se da postura crítica de Marx talvez seja imprescindível apropriar-se das conclusões e reflexões e a forma como chegou a elas, uma vez que o método e o conteúdo não parecem ser momentos distintos em sua obra.

\begin{tabular}{|l|l|l|l|l|}
\hline Q Povista Dialectus & Ano 5 & n. 12 & Janeiro - Julho 2018 & p. 439-461 \\
\hline
\end{tabular}




\section{A TEORIA CRÍTICA DE KARL MARX NAS PERSPECTIVAS DE...}

Rosalvo Schütz

Ou, em outras palavras: que ingrediente fundamental faz com que a teoria de Marx (especialmente em sua obra principal: $O$ Capital) possa ser considerada uma crítica e não uma simples descrição, diferenciando-se, assim, da obra de Hegel? E, por fim, como podemos, através da compreensão do caso de Marx, visualizar um horizonte crítico capaz de ser atualizado constantemente em nossas realidades históricas concretas, sem que, para tanto, precisemos ficar restritos às conclusões desse autor?

Como veremos, em Theodor Adorno e Enrique Dussel encontramos autores que, embora de tradições bastante diversas, confluem na sua abordagem e identificação da potencialidade crítica da teoria marxiana: no contexto da teoria crítica da Escola de Frankfurt, Adorno afirma que o diferencial crítico de Marx estaria justamente na sua capacidade de apontar para além daquilo que nos é apresentado como totalidade pela lógica do capital, ou seja, para aspectos não-idênticos do capital, ou ainda, na medida em que Marx não reduz o ser ao pensar (exposição a partir de certo princípio); E. Dussel, na perspectiva da Filosofia da Libertação e buscando compreender o potencial da teoria de Marx para essa filosofia, procura demonstrar que a afinidade dela com Marx está justamente no "desde onde" se produz a teoria: a partir do não-ser, do outro enquanto negado pelo sistema, portanto, para além da totalidade e a partir da exterioridade. Vejamos, exemplarmente, dois momentos argumentativos destes dois autores em relação ao tema.

\section{1- Theodor Adorno: $O$ caráter não-idêntico enquanto referência crítica}

Theodor Adorno sempre constantemente preocupado em diferenciar materialismo dialético de Marx daquilo que chamava de materialismo dogmático ou naturalístico a que a teoria desse autor teria sido reduzida nos horizontes do DIAMAT (Dialektische Materialismus) soviético. Seus argumentos se fundam, por exemplo, na convicção de que a totalidade objetiva do sistema capitalista, descrita por Marx em $O$ Capital, não é um simples reflexo ou reconstrução de uma realidade objetiva independente do sujeito. Entende que a descrição dessa totalidade - que supostamente se afirma para além e independentemente dos indivíduos através de uma dinâmica

\begin{tabular}{|l|l|l|l|l|}
\hline Q Poxista Dialectus & Ano 5 & n. 12 & Janeiro - Julho 2018 & p. 439-461 \\
\hline
\end{tabular}




\section{A TEORIA CRÍTICA DE KARL MARX NAS PERSPECTIVAS DE...}

Rosalvo Schütz

econômica própria - só pode ser compreendida em base a conceitos como, por exemplo, a troca e o valor de troca. Ora, a troca de equivalentes (com igual valor de troca) pressupõe a abstração do seu valor de uso. Valor de troca, portanto, só existe na medida em que há um conceito desse valor. Ora, aquilo que só existe na forma de conceito é evidentemente algo que transcende a pura naturalidade em base à qual o materialismo naturalístico pretende explicar a realidade. Esse momento do conceito ou, nas palavras de Adorno, o momento não material (nichtstoffliches Moment) (Adorno, 1974, p. 23) não reside apenas no observador ou na construção, mas é parte constituinte da própria coisa e da objetividade social. Afinal, a abstração da sociedade moderna não é algo que está apenas na cabeça de seus integrantes. Apesar de ser uma abstração real (Realabstraktion) como já afirmava Marx, essa sociedade continua sendo possível somente enquanto resultado também da abstração. A própria dialética não pode existir sem que se conserve permanentemente esse momento subjetivo ativo (reflexivo, pensante, em movimento) que não pode ser atribuído a uma matéria sem sujeito. Daí já se segue também, segundo Adorno, que a dialética não pode ser reduzida a um automatismo.

A própria possibilidade de pensar ou expor a realidade a partir de um princípio implica necessariamente a abstração-exclusão de elementos e aspectos que não se submetem à sua dinâmica. A crítica a uma realidade exposta a partir de um princípio, portanto, só se torna efetiva na medida em que aquilo que é excluído por ele, aquilo que o princípio não é e que, ao mesmo tempo, pressupõe seja evidenciado. Evitar a caída ou recaída no dogmatismo de princípio - onde não se percebe mais aquilo que este não é, enquadrando toda a realidade em conceitos prévios - seria, portanto, o desafio por excelência do pensamento crítico. A absolutização de qualquer princípio abstrato (mesmo que pretensamente materialista) significa reduzir o ser ao pensar, ou seja, cair no idealismo. A realidade passa, assim, a ser apenas registrada, classificada, ordenada, etc., a partir desse princípio. Com isso, segundo Adorno, perde-se a capacidade de pensar, transferindo para a filosofia e o pensar o typus próprio da burocracia, quando o pensamento se torna tautologia e é negada tanto a função ativa do sujeito quanto a primazia que o mundo (os objetos) tem sobre o pensar. Nesses casos, no dizer de Adorno, o pensador é degradado a burocrata. A própria teoria de Hegel, apesar de seu caráter

\begin{tabular}{|l|l|l|l|l|}
\hline Gonista Qialectus & Ano 5 & n. 12 & Janeiro - Julho 2018 & p. 439-461 \\
\hline
\end{tabular}




\section{A TEORIA CRÍTICA DE KARL MARX NAS PERSPECTIVAS DE...}

Rosalvo Schüitz

dialético, na medida em que se pretende apenas uma descrição (daí a sua referência à coruja), reduzindo tudo a certa identidade, de certa forma teria permanecido enredada nesse horizonte. Na medida em que Hegel teria posto a dialética a serviço de um sistema, teria eliminado o potencial crítico da dialética (Adorno, 1963). Dessa forma, Hegel teria ficado também comprometido com a manutenção da realidade que descreve, pois, segundo nosso autor, a “[...] identidade é a forma originária de ideologia” (Adorno, 2009, p. 128). O exemplo extremo dessa pretensão de dominação absoluta pôde ser diagnosticado, por exemplo, em sistemas totalitários como o estalinismo ou o nazismo, pois neles tudo “[...] deve ser usado, tudo deve lhes pertencer. A mera existência do outro é motivo de irritação. Todos os outros são 'muito espaçosos' e devem ser recolocados em seus limites, que são os limites do terror sem limites" (Idem, p. 151).

Negar a postura idealista - como forma de protesto contra o caráter ilusório e ideológico do idealismo - e, portanto, evitando recorrer primeiramente ao sujeito negando o primado dele, pode induzir a concepção materialista ao erro de negar completamente a função subjetiva. Esse perigo, segundo nosso autor, está permanentemente presente numa concepção materialista. Essa postura traduz-se geralmente na referência direta à realidade, como que recorrendo a algo perdido. A postura positivista ou de um materialismo mecanicista - que negam a função ativa do sujeito no processo de conhecimento e ação - acabam sendo apenas o reverso da mesma moeda idealista. Por isso se torna tão importante que o materialismo, apesar de negar a primazia do sujeito, consiga intermediar (vermitteln) seu conceito com a experiência subjetiva, marcada sempre por um corpo (Leib) de um ser humano individual que realiza um ato cognitivo. Ou seja, garantir a primazia do objeto de forma alguma pode significar a anulação da função ativa do sujeito, pois isso significaria a reificação desse sujeito, quando não de toda a realidade pretensamente descrita ${ }^{8}$.

Com essas reflexões, que estão na base da concepção de dialética negativa, Adorno busca diferenciar sua concepção de dialética da de Hegel. Segundo Adorno, é “[...] a coisa, e não o impulso à organização própria do pensamento, que provoca a

8 Quanto a questão da primazia do objeto, ver os textos de Leo Mar (2006): "Materialismo e primazia do objeto em Adorno", e Schütz (2012) "Refúgio da liberdade: sobre a concepção de filosofia em T. Adorno".

\begin{tabular}{|c|c|c|c|c|}
\hline Revita Dialectus & Ano 5 & n. 12 & Janeiro - Julho 2018 & p. $439-461$ \\
\hline
\end{tabular}




\section{A TEORIA CRÍTICA DE KARL MARX NAS PERSPECTIVAS DE...}

Rosalvo Schütz dialética" (2009, p. 126). Ora, o que isso quer dizer? Simplesmente que não existe pensar sem que o pensamento seja atingido por algo que não é pensamento. A origem da filosofia na admiração, ou seja, na ignorância já apontaria para tal. Um sistema com pretensão de explicação total não pode senão ser expressão ideológica da pretensão de dominação absoluta (mesmo que inconsciente): "É preciso se opor à totalidade, imputando-lhes a não-identidade consigo mesma que ela recusa segundo seu próprio conceito" (Idem, pp. 128-129). Ou seja, é preciso demonstrar a insuficiência da totalidade apresentada (mesmo que seja a hegeliana), evidenciando o que foi reprimido e escamoteado pela mesma.

A dialética no sentido materialista, proposta por Adorno, portanto, leva a sério a totalidade apresentada e sua pretensão de verdade, mas questiona-a na medida em que evidencia seu caráter não-idêntico, entendido aqui como aquela realidade (Ser) que está para além do pensar, para além daquilo que é apresentado a partir de algum princípio explicativo: "Colocar a dialética puramente na conta do sujeito, eliminar a contradição por assim dizer por meio de si mesma, também traz como resultado a eliminação da dialética, na medida em que ela é estendida à totalidade" (Idem, p. 139). Da mesma forma, seria uma ilusão fantasmagórica "[...] atribuir cegamente a dialética a uma matéria sem sujeito" (Adorno, 1974, p. 22) ${ }^{9}$. Ela, portanto, não pode jamais se fechar sobre si mesma sem incorrer na sua degradação em ideologia, pois se "[...] a dialética se fechasse totalmente em si mesma, então ela já seria aquela totalidade que remonta ao princípio da identidade" (Adorno, 2009, p. 156) e por isto, segundo Adorno, "cabe à filosofia pensar aquilo que é diverso do pensamento e o que transforma pela primeira vez em pensamento" (Idem, p. 165).

A partir desse horizonte, Adorno pôde afirmar a necessidade da "primazia do objeto" para que possa de fato existir dialética no sentido crítico. Essa primazia é, em verdade, o reconhecimento dos limites do pensar frente ao ser, frente à realidade. Kant, segundo Adorno, jamais teria - apesar da revolução copernicana do conhecimento realizada por ele - se deixado dissuadir do primado do objeto, pois, mesmo afirmando a centralidade do sujeito na constituição do conhecimento, Kant jamais teria cedido à

9 Todos os textos referidos a textos originais em alemão são aqui traduzidos pelo autor desse artigo.

\begin{tabular}{|l|l|l|l|l|}
\hline Q Ronista Qialectus & Ano 5 & n. 12 & Janeiro - Julho 2018 & p. 439-461 \\
\hline
\end{tabular}




\section{A TEORIA CRÍTICA DE KARL MARX NAS PERSPECTIVAS DE...}

Rosalvo Schütz

tentação de querer abarcar todo o ser com o conhecer. A coisa em si kantiana significa a garantia ou mesmo a reserva crítica contra tal, já que nenhuma forma de conhecimento pode, em momento algum, afirmar saber a coisa em si e, portanto, é também forçada a reconhecer humildemente seu limite. A coisa em si em Kant é, pois, um sinal da insuficiência do sujeito (Adorno, 2009, p. 159).

Essa reserva crítica, no entanto, teria sido eliminada, por exemplo, em Hegel. A afirmação do idealismo absoluto de Hegel só se torna possível à custa da negação daquilo que ultrapassa a esfera do pensar. Hegel, no entanto, conforme ele mesmo afirma, é apenas a autoconsciência de sua época. Ou seja, uma época em que o sujeito pensante tem pretensões de domínio absoluto sobre si e o mundo. O custo desse processo é a abstração/negação de tudo o que não se enquadra em um sistema previamente constituído. Para Adorno, sempre que uma realidade é enquadrada em conceitos prévios anulando a sua singularidade, manifesta-se a pretensão de dominação absoluta expressa de forma exemplar pelo idealismo hegeliano. Evidentemente esse idealismo pode ser expresso também sob o disfarce materialista, sua característica fundamental é o não reconhecimento daquilo que vai para além do esquematismo prévio.

Reconhecer a primazia do objeto, no entanto, não implica recair no positivismo que nega a função ativa do sujeito e do pensamento. Deixar se afetar pelo objeto não implica sucumbir a ele, pelo contrário, é a própria condição de possibilidade do pensamento: "Pensar mesmo é uma atitude, e quem no pensamento não se relaciona simultaneamente com a realidade, de fato nem mesmo pensa" (Adorno, 1974, p. 237). Existiria, por isso, certa afinidade entre a filosofia e a arte (Adorno, 1973, p. 209), na medida em que também ela representa aquilo que ainda não é conceito, aquilo que ainda não é "enquadrável” e ordenável. A filosofia, no entanto, e diferentemente da arte, representa esses aspectos não-idênticos apenas através do pensamento, do esforço do conceito. Esse pensamento, no entanto, não acontece em torno de quimeras, mas exige o esforço do conceito, ou seja, a abertura para o mundo. Por isso, para Adorno, além do parentesco com a arte, o pensar tem também um parentesco com o trabalho, ou seja, o sujeito se funde de forma ativa com o objeto, produzindo, assim, uma síntese: o conceito. A diferença é que o conceito, ao contrário do produto tangível do trabalho, só tem sentido

\begin{tabular}{|l|l|l|l|l|}
\hline Gonista Qialectus & Ano 5 & n. 12 & Janeiro - Julho 2018 & p. 439-461 \\
\hline
\end{tabular}




\section{A TEORIA CRÍTICA DE KARL MARX NAS PERSPECTIVAS DE...}

Rosalvo Schütz

dentro de uma constelação de significados (outros conceitos) expostos a toda sorte de situações históricas, sociais, culturais, etc. A produtividade explicativa dos conceitos está sempre situada em constelações em movimento, em devir. A construção delas depende, em grande medida, do esforço do sujeito pensante, mas também da capacidade de ele se deixar afetar pelo mundo, pelos objetos. Atribuir conteúdos prévios aos conceitos ou mesmo fixá-los em esquematismos seria o mesmo que lhes retirar o seu caráter dinâmico, a sua vida. O fetiche dos conceitos tem, segundo Adorno, sua origem nessa tentativa de domínio absoluto sobre os objetos e de atribuir conteúdos petrificados aos conceitos. Na medida em que a capacidade de se deixar afetar pelas coisas e apreender algo delas mesmas é atrofiada, a capacidade de reflexão filosófica e de teoria crítica também vai se inviabilizando (Adorno, 1973, p. 208).

Esse horizonte teórico amplo da teoria de Adorno, aqui rápida e resumidamente apontado, é, em grande medida, assemelhado com a postura teórica de $\mathrm{K}$. Marx. O próprio Adorno faz questão de enfatizar essa proximidade, pois, segundo ele, Marx não apenas se voltou criticamente contra o idealismo hegeliano, mas também contra a realidade de cuja autoconsciência esse idealismo se dizia portador. Segundo Adorno, os momentos especificamente materialistas e críticos de Marx situam-se exatamente em aspectos de sua teoria que não se enquadram no conceito de sistema, embora o considerem enquanto uma referência negativa. Segundo Adorno, em Marx o sistema é considerado enquanto tal, mas apenas negativamente, “[...] no qual se tenta compreender a unidade sistemática da sociedade burguesa, capitalista e se lhes colocar a questão se ela de fato é esta unidade inquebrantável [...] a qual ela mesma se dá e apresenta" (Idem, p. 216). Nesse sentido, a teoria de Marx implicou também certa crítica à filosofia "[...] na medida em que esta crê poder deduzir a realidade a partir de algum princípio, qualquer que seja este princípio" (Idem, p. 255). Essa crítica pôde, no caso de Marx, muito bem ser dirigida também contra a sociedade capitalista, uma vez que o “[...] princípio da troca, a redução do trabalho humano ao conceito universal abstrato do tempo médio de trabalho, é originalmente aparentado com o princípio da identificação" (Adorno, 2009, p. 138). Segundo nosso autor, essa postura crítica em relação a qualquer pensamento com pretensões totalizantes constitui o principal impulso materialista da

\begin{tabular}{|l|l|l|l|l|}
\hline Q Poxista Dialectus & Ano 5 & n. 12 & Janeiro - Julho 2018 & p. 439-461 \\
\hline
\end{tabular}




\section{A TEORIA CRÍTICA DE KARL MARX NAS PERSPECTIVAS DE...}

Rosalvo Schütz

teoria de Marx. É a partir desses aspectos e impulsos não redutíveis ao sistema que se constitui a possibilidade da crítica na teoria de Marx.

Se for assim, como então entender a postura hegeliana de Marx, na medida em que, por exemplo, em $O$ Capital, busca fazer uma exposição imanente da totalidade da sociedade burguesa a partir de sua dinâmica interna? Não se deveria esperar, depois do que foi dito até aqui, que Marx jamais deveria querer pensar a sociedade enquanto um sistema? De fato, ao que tudo indica, Marx levava muito a sério a estrutura de sociedade tal como a percebia e mesmo sistemas filosóficos como o de Hegel ou teorias como as dos economistas da época. Também não lhes contrapunha um ideal externo. Para enfrentar essa aparente contradição da filosofia de Marx, Adorno (1973, p. 259 ss.) se apoia exemplarmente em um aspecto desse pensador: o significado das forças produtivas e das relações de produção na sociedade atual. Segundo Adorno, a grande diferença de Marx em relação a muitos anarquistas e socialistas da época é que ele não afirma simplesmente que "isso tudo não é verdade"! Simultaneamente, no entanto, evidencia os significativos limitados desses termos/realidades.

Seguindo uma pista deixada por Hegel, mas acrescentando-lhe um ingrediente crítico, Marx quer pôr o sistema em movimento a partir das forças que são inerentes a ele mesmo, a fim de poder transformá-lo. No dizer de Adorno, Marx como que lançaria a pergunta: "É esta sociedade que vocês pregam realmente idêntica ao seu conceito? Este mudo mundo das trocas livres e justas corresponde realmente a uma sociedade livre e justa?" (Idem, p. 261). Ao mesmo tempo em que Marx, por exemplo, demonstra que, do ponto de vista do sistema, de fato existe a troca de equivalentes, ele mostra também que, em um ponto crucial, esta equivalência é questionável: quando se trata da mercadoria trabalho, pois, apesar de a troca ser justa do ponto de vista da equivalência (o patrão paga tanto ao trabalhador quanto ele precisa para repor a força de trabalho dispensada), os custos da reprodução dessa força são menores do que os resultados das horas de trabalho despendidas, gerando, assim, a famosa mais-valia. Assim, expondo passo a passo a sistemática da sociedade burguesa, Marx vai evidenciar aspectos não idênticos em base aos quais o sistema eventualmente pode ser posto em questão: vestígios de uma aparência ideologicamente enganadora. É nesse sentido que,

\begin{tabular}{|l|l|l|l|l|}
\hline Gonista Qialectus & Ano 5 & n. 12 & Janeiro - Julho 2018 & p. 439-461 \\
\hline
\end{tabular}


segundo Adorno, é possível "[...] denominar o sistema marxiano um sistema negativo ou crítico, uma teoria inteiramente crítica" (Idem, p. 262). O mundo pode, portanto, ser um sistema (que não pode ser desprezado!), mas um sistema que é imposto às pessoas como algo que lhes é estranho: "Isto é, um sistema enquanto ideologia, e este todo, que em Hegel deveria ser a verdade, na teoria marxiana seria uma inverdade" (Idem, p. 263). Um pensamento que seja de fato livre parece, portanto, ser incompatível com um sistema com pretensões de explicação absoluta, uma vez que ele tende a se fundas em uma pretensão totalitária.

O caráter efetivamente crítico, segundo Adorno (Idem, p. 268) da teoria de Marx, por isso, seria menos tributário da conhecida pretensão de pôr Hegel de cabeça para baixo, do que de um elemento materialista ou mesmo naturalista vinculado à sua ideia de produtividade, incluindo aí os conceitos de "força produtiva" e de "relações de produção". Vejamos.

O produto do processo de trabalho é, em princípio, um valor de uso: produto natural que agora também presentifica o trabalho humano. Não é mais puro objeto, mas também não é puro sujeito, é algo intermediário, mas é uma coisa-produto útil para os seres humanos. Como se sabe, embora a produção e as qualidades dos produtos sejam um pressuposto de toda e qualquer mercadoria, elas pouco importam do ponto de vista do valor de troca, são como que um "mal necessário" para este. O sistema de troca de mercadorias, no entanto, não consegue eliminar esse momento produtivo (de interação com a natureza) e nem da qualidade dos produtos. Por isso se pode dizer que o "[...] conceito diretamente materialista de produtividade tem como centro o conceito de uso e é orientado para a coisa. No sentido da sociedade burguesa 'produtivo' significa bem outra coisa" (Idem, p. 272). Ou seja, ao não sucumbir àquilo que é produtivo apenas na sociedade burguesa (orientado para a produção de valor de troca) Marx garante um referencial crítico que lhe permite desmascarar a própria sociedade burguesa a partir dos seus conceitos mais fundamentais, como, no caso, o da produtividade. No interior da dinâmica da sociedade moderna, o significado desta teve de ser profundamente reduzido, uma vez que é considerado produtivo apenas aquele trabalho que se adéqua ao processo de valorização do valor: que produz valor de troca. Assim, essa sociedade que é

\begin{tabular}{|l|l|l|l|l|}
\hline Q Ooxista Dialectus & Ano 5 & n. 12 & Janeiro - Julho 2018 & p. 439-461 \\
\hline
\end{tabular}




\section{A TEORIA CRÍTICA DE KARL MARX NAS PERSPECTIVAS DE...}

Rosalvo Schütz

apresentada como a ideal não reconhece como trabalho produtivo tudo o que não se deixe reduzir aos seus ditames. O único critério da sociedade burguesa para dizer que algo é produtivo ou não são os resultados do mercado, é a sua capacidade de gerar mais valor de troca.

Marx estaria se referenciando ao trabalho do ponto de vista do seu uso e isso lhe garantiria um olhar não idêntico ao sistema, permitindo-lhe a crítica da redução operada pela sociedade burguesa, por demonstrar a sua inverdade, ou seja, o seu caráter ideológico. Adorno localiza um lugar específico da não-identidade em Marx e, simultaneamente, aponta para a diferença da teoria de Marx em relação a Hegel: "Se não mais se retivesse, de nenhum homem, uma parte de seu trabalho vital, então a identidade racional seria alcançada e a sociedade estaria para além do pensamento identificador. Isso se aproxima muito de Hegel” (2009, p. 12). Na medida, pois, em que Marx demonstra que a redução do trabalho humano a um tempo médio de trabalho (valor de troca) não abarca toda a realidade do trabalho e da produtividade humana, o potencial crítico de sua teoria é revelado.

Com esse exemplo sobre o caráter crítico da teoria de Marx, Adorno certamente evidencia o que significa a sua afirmação em relação a teoria de Wittgenstein, afirmando que "[...] de fato só se pode filosofar quando na consciência a gente já tenha a impossibilidade de expressar aquilo que não se deixa expressar" (1974, p. 289). Se Marx não tivesse tentado fazer isso, ou seja, dizer aquilo que o sistema não permite dizer, teria permanecido hegeliano ou, no máximo, teria se tornado um economista melhorado.

\section{2- Enrique Dussel: “exterioridade” enquanto referência crítica}

Enrique Dussel em muitos momentos dialogou com a teoria de Karl Marx, buscando apropriar-se dela numa perspectiva latino-americana. Evidentemente essa não é uma postura/atitude autojustificável sem mais. Como fazer de um pensador europeu, como Marx, uma referência para uma postura teórica que busca fundamentalmente libertar-se do eurocentrismo? Seria possível apropriar-se da teoria ou da postura teórica dele a fim de fundamentar e erigir um pensamento baseado em algo genuinamente latino-

\begin{tabular}{|l|l|l|l|l|}
\hline Gonista Qialectus & Ano 5 & n. 12 & Janeiro - Julho 2018 & p. 439-461 \\
\hline
\end{tabular}




\section{A TEORIA CRÍTICA DE KARL MARX NAS PERSPECTIVAS DE...}

Rosalvo Schütz

americano, capaz de fornecer suporte para uma libertação frente ao eurocentrismo? Não implicaria isso o aprisionamento teórico dentro de um horizonte ou, melhor, dentro de uma totalidade erigida pela própria cultura do "centro"?

A fim de enfrentar essa questão e buscando demonstrar que o pensamento de Marx poderia ser produtivo para uma filosofia comprometida com a libertação latinoamericana, Dussel faz uma abordagem bastante peculiar da teoria dele. Faz isso ao demonstrar que Marx não pensa desde o "Ser", mas sim desde o "não-ser”, ou seja, desde uma exterioridade, e, nessa postura, estaria a sua afinidade com a Filosofia da Libertação. À apropriação da teoria de Marx nessa perspectiva pode ser atribuído um caráter muito peculiar, justamente pelo seu ponto de partida: "La 'relectura' latinoamericana de Marx es única, distinta, original por su 'punto de partida': la miseria real, histórica y creciente de nuestro pueblo" (Dussel, 1990, p. 333). Na medida em que evidencia e fundamenta esse potencial da teoria de Marx para a Filosofia da Libertação, na realidade, Dussel acaba evidenciando o que, na sua perspectiva, constituiria o caráter crítico da teoria de Marx. Buscaremos aqui demonstrar como Dussel elaborou essa questão.

No livro editado em 1988 sob o título Hacia un Marx Desconocido: un comentário de los manuscritos del 61-63, Dussel afirma que o que assegura à teoria de Marx a garantia da criticidade é justamente o trabalho vivo (p. 297). O trabalho vivo seria uma espécie de reserva crítica contra qualquer forma de organização econômica na qual os produtos do trabalho tendam a ser fetichizados. O trabalho vivo seria "[...] el 'desdedónde' se efectúa esta crítica (es decir, el 'punto de partida' radical y primero de todo el pensar de Marx)" (Idem, p. 290). Segundo nosso autor, toda a teoria de Marx é perpassada por esse pressuposto crítico, sendo, inclusive mais marcante que o caráter descritivo de sua obra.

A partir daí pode-se afirmar que Marx exerceu uma dupla crítica:

[...] no sólo crítica de textos (de la economía política clásica o vulgar capitalista); sino, y principalmente, crítica de la realidad capitalista, o importante é que em ambos os momentos a crítica, "se efectúa 'desde' um certo punto de vista. En concreto, histórica y socialmente, desde el proletariado

\begin{tabular}{|c|c|c|c|c|}
\hline Qovita Dialectus & Ano 5 & n. 12 & Janeiro - Julho 2018 & p. $439-461$ \\
\hline
\end{tabular}




\section{A TEORIA CRÍTICA DE KARL MARX NAS PERSPECTIVAS DE...}

Rosalvo Schütz

(clase social explotada y subsumida por el capital); pero esencialmente [...] desde el trabajo vivo (Idem, p. 293).

Na medida em que o trabalho vivo é a única fonte de toda a criação de valor, também seria somente ele que pode se tornar a referência capaz de se opor ao trabalho objetivado, ao trabalho morto convertido em simples valor de troca, tal como é levado em conta pela lógica do capital. O capital, no entanto, se apresenta com pretensões de totalidade: dominar tudo com seu princípio de produção de valor de troca e mais-valia. Segundo Dussel, no entanto, o trabalho vivo não é subsumido por essa totalidade, por mais que a lógica do capital ideologicamente assim o represente.

A crítica à lógica do capital, portanto, teria se tornado possível em Marx, não pela simples descrição teórica mais apurada dessa lógica, mas, sim, na medida em que, apesar de levar a sério a totalidade que se apresenta do ponto de vista do capital, não ter aceitado reduzir toda a realidade a esse ponto de vista ${ }^{10}$ : "La 'totalidad' es la categoría por excelencia de toda ontología, ya que el ser es el horizonte de la totalidad de un mundo o sistema dado, por ej. del capital" (Idem, p. 365). A totalidade do capital, portanto, seria apenas a totalidade de um determinado sistema dado. O "desde onde" Marx argumentaria de forma crítica em relação a essa totalidade não seria desde o interior do capital, mas, sim, de sua exterioridade. Segundo Dussel, poder-se-ia, portanto, afirmar que a categoria central para Marx, e a partir da qual a teoria dele pode ser considerada uma teoria crítica, é a exterioridade e não a totalidade.

Marx poderia, assim, ser inserido em uma tradição crítica e anti-hegeliana que vem desde Schelling e passa por Feuerbach e que não aceita a redução da realidade ao pensar, ou, na linguagem de Dussel, que não aceita reduzir a realidade a uma totalidade dada. A crítica a uma totalidade dada se viabiliza na medida em que existe algum referencial exterior "desde onde" seja possível estabelecer a crítica, um referencial crítico. E é nesse sentido que, para Dussel, a crítica do capital "[...] se efectuará desde la exterioridaddel 'trabajo vivo'. 'Exterioridad' real más allá, trascendental, del ser del

10 Essa parece ser uma das principais diferenças de teoria de Marx em relação à de Hegel, aproximando-o mais da tradição que remonta a Schelling. A esse respeito, ver Schütz (2009): "Sensibilidade Emancipatória: Schelling, Feuerbach e Marx a contrapelo da tradição".

\begin{tabular}{|l|l|l|l|l|}
\hline Q Rovista Dialectus & Ano 5 & n. 12 & Janeiro - Julho 2018 & p. 439-461 \\
\hline
\end{tabular}




\section{A TEORIA CRÍTICA DE KARL MARX NAS PERSPECTIVAS DE...}

Rosalvo Schütz

capital, del valor (como cosa efectuada). La 'realidad' del 'no-capital' [...] es el ámbito desde donde se cumple la critica de la totalidad del valor que se valoriza (cosa): la crítica del capital" (Idem, p. 293). A aceitação do caráter absoluto do capital como totalidade, ou seja, a não percepção da relação que tem com o trabalho vivo, seria a fonte de todo o fetischismo. A crítica, portanto, implicaria a desconstituição do fetichismo. Essa desfetichização, no caso aqui em questão, só é possível na medida em que se restabelece a relação entre o trabalho morto (traduzido no valor de troca, ou seja, no capital) com o trabalho vivo, com a subjetividade humana sem valor algum ou, como expressa Dussel citando Marx, com “o homem de carne e osso" (Idem. p. 295).

Em um texto específico sobre a exterioridade no pensamento de Marx (Idem, p. 365), Dussel procura demonstrar que a categoria da exterioridade pode ser vista como sendo uma categoria central na obra de Marx, desde a sua juventude até as suas últimas obras. Dussel afirma que essa exterioridade, enquanto condição prática da crítica à totalidade, é também “[...] el lugar de la realidad del otro, del no-Capital, del trabajador viviente en su corporalidad todavía no subsumida en el capital" (Idem, p. 366). O outro do capital, ou seja, aquilo que não pôde ou ainda não é subsumido pela pretensão de totalidade deste, é que passa a ser o "desde onde" se viabiliza a crítica. Essa postura, consciente ou não, se faz presente, segundo Dussel, em toda a produção teórica de Marx.

De fato, já em alguns de seus primeiros escritos Marx argumenta desde a perspectiva daqueles não incluídos no sistema (os outros), seja no caso do trabalho de jornalista em defesa dos pobres que se apropriam da lenha para se aquecer "desrespeitando" a instituição da propriedade privada, seja na descoberta do proletariado (em A Questão Judaica, de 1843) enquanto sofredor de uma miséria que nasce a partir de uma pobreza produzida por uma ordem universal. A libertação do proletariado dessa condição indica para um "além de" da dita totalidade dominante que o produziu. O seu estado de pobreza "reclama la negación de la dominación" (Idem. p. 367). Em 1844, nos Manuscritos Econômico-Filosóficos, essa postura é verificável em diversos momentos. Nessa obra Marx enfatiza que quem não se enquadra no sistema da economia política vigente é considerado simplesmente um nada diante do mesmo sistema. Recordemos a conhecida passagem de Marx:

\begin{tabular}{|l|l|l|l|l|}
\hline Q Ooxista Dialectus & Ano 5 & n. 12 & Janeiro - Julho 2018 & p. 439-461 \\
\hline
\end{tabular}




\title{
A TEORIA CRÍTICA DE KARL MARX NAS PERSPECTIVAS DE...
}

Rosalvo Schütz

\begin{abstract}
Deste modo, a economia política não conhece o trabalhador desocupado, o homem que trabalha, na medida em que ele se encontra fora da relação de trabalho. O burlão, o ladrão, o pedinte, o desempregado, o faminto, o miserável e o criminoso são figuras de homem que não existem para a economia política, mas só para outros olhos, para os do médico, do juiz, do coveiro, do burocrata, etc. São fantasmas que se situam fora do seu domínio (Marx, 1964, p. 176).
\end{abstract}

É, no entanto, justamente a partir da perspectiva desse ser humano ignorado pela economia política, situado fora, que Marx articula a sua crítica ao sistema. Ele representa o "além de" da totalidade do capital. O fato de ter de deixar de ser um ser humano autônomo e passar a ser um ser alienado, vendido e negado - na medida em que é subsumido pelo capital que tende a reduzi-lo a trabalhador assalariado - só pode ser criticado na medida em que não é totalmente reduzido ao capital, enquanto é o outro desse capital, enquanto se mantém uma reserva crítica, que permanece não subsumida. Nesse sentido, Dussel afirma que o “[...] 'outro' de la 'totalidad', en la 'exterioridad', es nada para el ser del sistema, pero es todavía real. La 'realidad' del otro resiste más allá del 'ser' de la totalidad. El trabajador no-asalariado, real, exterior al capital como totalidad es la exteridad" (Dussel, 1988, p. 368).

Mais tarde, nos Grundrisse de 1857, Marx faz questão de enfatizar que o trabalho enquanto não-capital - trabalho não objetivado enquanto um não-valor coincide com a imediata corporeidade (Leiblichkeit) do trabalhador. Esse trabalho, que ao mesmo tempo é a "antítesis, como existencia contradictoria del capital", é também "presupuesto por el capital" (Marx apud Dussel, 1988, p. 368). Ou seja, nesse momento Marx já percebera que aquilo que é negado pela lógica do capital é que se constitui enquanto referência "desde onde" se torna possível articular a crítica. O trabalhador enquanto tal é o outro do capital ainda não reduzido a "trabalho assalariado". Assim, pode-se dizer que o trabalho vivo, enquanto não subsumido pelo princípio do capital, assume para Marx uma positividade crítica. Donde Dussel conclui que a "articulación práctica de la exterioridad a la corporalidad desnuda del trabajador es la condición para una teoría crítica" (Idem, p. 369). O fetichismo do capital (ou seja, sua pretensão de totalidade) - que consiste em se apresentar como criador de valor a partir de si mesmo só pode, pois, ser desmascarado a partir daquilo que ele não quer admitir, mas do qual

\begin{tabular}{|l|l|l|l|l|}
\hline Q Ooxista Dialectus & Ano 5 & n. 12 & Janeiro - Julho 2018 & p. 439-461 \\
\hline
\end{tabular}




\section{A TEORIA CRÍTICA DE KARL MARX NAS PERSPECTIVAS DE...}

Rosalvo Schütz

depende, ou seja, a partir do seu outro: o trabalho vivo enquanto a única fonte criadora de valor (exnihilo, como diria Marx).

O lugar lógico ocupado pelo "outro" enquanto "exterioridade" e, por isso, enquanto condição de possibilidade da crítica, indubitavelmente permanece na obra mais expressiva da Marx: $O$ Capital. A corporeidade (Leiblichkeit) viva (que é forçada a deixar que "cortem seu próprio couro" na medida em que o trabalhador é forçado a vender seu trabalho vivo em forma de trabalho abstrato no mercado) do ser humano continua constituindo essa referência. A exposição da totalidade constituída pelo capital, empreendida por Marx nessa obra, não é uma simples exposição justamente por ser uma exposição desde aquilo que o capital não é, desde sua exterioridade. Ao que tudo indica no caso de $O$ Capital, essa exterioridade é o trabalho vivo que "[...] constituirá el punto de apoyo de la criticidad de Marx" (Idem, p. 372).

Essa perspectiva crítica desenvolvida por Marx, segundo Dussel, estaria inserida em uma tradição crítica que remontaria a Schelling. Habermas teria o mérito de ter sido um dos primeiros a indicar que Marx teria feito na economia algo parecido com o que Schelling fez na teologia. De forma que, por meio dos apontamentos de Habermas, se poderia concluir que "[...] lo que Schelling criticó de Hegel en filosofía fue tomado por Marx explícitamente en economía y está filosóficamente implícito en su 'núcleo racional' ético-filosófico. Este 'núcleo' adeuda a Schelling más que a Hegel: es essencialmente schellinguiano, y sólo formalmente hegeliano" (Dussel, 1990, p. 344). Dessa forma se poderia afirmar que Marx, por exemplo, ao falar do trabalho vivo, estaria incluído na tradição schellinguiana segundo a qual existe uma "fonte criadora" do "Ser". Ao contrário de Hegel, que, em sua Lógica, partiria sempre do Ser, Marx, em O Capital, partiria do não-ser, do nada, ou seja, da capacidade criadora do trabalho vivo ${ }^{11}$. Ou, como

11 Apesar de conhecerem muito bem o pensamento de Schelling, autores como E. Bloch e o próprio J. Habermas não teriam conseguido reelaborar o pensamento dele desde essa hipótese, fixando-se, portanto, no Ser ao estilo hegeliano e perdendo, por isso, o impulso crítico fundamental (Dussel, 1990, p. 352). Por esse motivo, também '[...] parece que los marxistas del 'centro' - el llamado 'marxismo occidental' de Lukács a Marcuse, principalmente - siguen a Hegel desde la izquierda y rechazan a Schelling como reaccionario - aun que con diferencias. [...] En cambio, los marxistas de la 'periferia' tienden a negar a Hegel, para situarse sin saberlo a la izquierda de Schelling (como Kierkegaard, Feuerbach y el mismo Marx desde 1842 y, en especial, luego del "viraje" ante el populismo ruso a partir de 1868)" (Dussel, 1990, pp. 332-333).

\begin{tabular}{|l|l|l|l|l|}
\hline Q Rovista Dialectus & Ano 5 & n. 12 & Janeiro - Julho 2018 & p. 439-461 \\
\hline
\end{tabular}




\section{A TEORIA CRÍTICA DE KARL MARX NAS PERSPECTIVAS DE...}

Rosalvo Schütz

afirma Dussel, "[...] de manera que lo que Schelling situaba en referencia al 'Absoluto' creador, Marx lo situará antropológica y económicamente con respecto al 'trabajo vivo' creador" (Idem, p. 351).

O trabalho vivo é, pois, o pressuposto oculto do próprio capital, embora seja nada do ponto de vista de sua lógica interna. Este pressuposto não é tematizável a partir dele mesmo. Ele é o não-ser, o Outro dele mesmo. "El 'trabajo vivo' es así la 'fuente meta-física', o que guarda exterioridad con respecto al capital como tal (como 'totalidad')" (Idem, p. 371). E é por isso que ele é o "principio 'meta-físico' real y crítico del capital como "totalidad" (Idem, p. 379). E é justamente essa exterioridade ("nos fantasmas que se situam fora do reino do seu domínio") o ponto de partida desde onde se garante o teor crítico da uma teoria.

A referência crítica de Marx seria, pois, algo anterior/exterior ao próprio capital e específico de sua época: “[...] el 'hecho', empírico ineludible y frontal: la miseria, la pobreza del trabajador inglés en la segunda parte del siglo XIX" (Dussel, 1990, p. 367). O experimento de Marx de expor, de forma crítica, a lógica do ser-Capital evidenciaria um potencial crítico de sua teoria que ultrapassa os limites históricos específicos dessa crítica. Marx teria evidenciado o que o autor chama de "núcleo racional ético filosófico", uma espécie de marco teórico a partir do qual se tornaria possível desenvolver uma teoria crítica até mesmo em outros tipos de sociedade (na época o autor tinha em mente o chamado "socialismo real" da União Soviética). Assim, a teoria de Marx, por exemplo, poderia continuar sendo uma referência para a elaboração de uma teoria crítica em momentos e em formas específicas de sociedade. Aponta-se, assim, por exemplo, para o potencial dela no contexto latino-americano. Nesse caso específico, no entanto, o “'No-ser' de un pueblo empobrecido es el punto de partida de la 'teoría' (como comprensión de sus causas) y de la 'praxis' (como acción revolucionaria)" (Idem. p. 367). Ou seja, eventualmente não apenas e necessariamente o proletariado industrial da época de Marx pode ocupar essa referência crítica a partir de onde se viabilizou a crítica de Marx.

\begin{tabular}{|l|l|l|l|l|}
\hline Q Rovista Dialectus & Ano 5 & n. 12 & Janeiro - Julho 2018 & p. 439-461 \\
\hline
\end{tabular}




\section{3- Conclusão:}

A convergência quanto ao que dá identidade crítica à teoria de K. Marx é evidente: a produtividade viva em Adorno e o trabalho vivo em Dussel. Aquilo que é nãoidêntico à produtividade do sistema da valorização do valor e o Outro, o exterior à totalidade apresentada. Ambos enfatizam que a originalidade crítica da teoria de Marx se deve à sua capacidade de se situar para além do sistema. Embora esta postura ainda não seja condição suficiente para o desenvolvimento de uma teoria crítica (pois o esforço do conceito certamente é insubstituível), a capacidade de deixar se afetar por aquilo que o sistema não é indispensável para o desenvolvimento da uma teoria crítica.

Como a realidade humana e social, no entanto, é marcada sobremaneira pela sua própria historicidade e mudança, uma teoria crítica jamais pode ser algo estanque ou orientada por sistemas, automatismos e ou conceitos previamente estabelecidos: isso significaria a exclusão do outro, do não-idêntico, histórica, singular e socialmente situado. Seria degradar a dialética à um idealismo. Se Marx tivesse sido apenas um economista melhorado ou se teria apenas "posto Hegel de cabeça para baixo" - fixado, portanto, na coruja enquanto representação da filosofia - sua teoria não seria uma teoria crítica. A insuficiência tanto dos economistas quanto de Hegel pode ser demonstrada justamente pelo fato de não ultrapassarem os limites do sistema, da identidade. Essa insuficiência pôde ser superada em Marx pelo fato de sua teoria ser elaborada desde o que não pode ser considerado pelo sistema: o trabalho e a produtividade viva. A fragilidade do sistema é evidenciada justamente no momento em que seus pressupostos ocultos e não tematizáveis do ponto de vista de sua dinâmica interna são explicitados. É neles que se situam os potenciais revolucionários. É a partir deles que se pode visualizar “o que pode ser, mas que ainda não é”. A naturalização ou a pretensão de necessidade do sistema fica, assim, abalada e os potencias reprimidos, mas latentes, podem eventualmente ser liberados.

Pode-se afirmar, portanto, que uma teoria crítica pressupõe algo que não se deixa reduzir a conteúdos: é antes uma postura marcada pelo "desde onde" ela é construída. Quem não consegue fazer teoria a partir do não-idêntico, da exterioridade, só

\begin{tabular}{|c|c|c|c|c|}
\hline Revista Dialectus & Ano 5 & n. 12 & Janeiro - Julho 2018 & p. $439-461$ \\
\hline
\end{tabular}




\section{A TEORIA CRÍTICA DE KARL MARX NAS PERSPECTIVAS DE...}

Rosalvo Schütz

pode fazer teoria tradicional, não só porque sucumbe frente ao impulso organizador da razão instrumental e da petrificação dos conceitos, mas também porque sua visão do sistema-totalidade só pode ser insuficiente: está cego diante do que pode ser mas ainda não é na realidade histórico-social em que vive. A naturalização das relações sociais na forma como elas se apresentam e a crescente indiferença social, portanto, parece caminhar, lado a lado, com o atrofiamento da nossa capacidade utópica e crítica.

Por fim, salientamos que, ao que tudo indica, há uma grande afinidade eletiva entre a Filosofia da Libertação e a Teoria Crítica (na perspectiva da Escola de Frankfurt). A fertilidade desta aproximação aqui indicada - com o exemplo em torno do caráter crítico da teoria de Marx - certamente se apresenta como um desafio para um pensamento que se pretenda crítico e libertário.

\section{REFERÊNCIAS:}

ADORNO, Theodor. Dialética negativa. Tradução: Marcos Antonio Casanova. Rio de Janeiro: Zahar, 2009.

ADORNO, Theodor. Drei Studienzu Hegel. Frankfurt: Suhrkamp, 1963.

ADORNO, Theodor. Philosophische Teminologie zur Einleitung. Band 1. Frankfurt am Main: Suhrkamp, 1973.

ADORNO, Theodor. Philosophische Teminologie zur Einleitung. Band 2. Frankfurt am Main: Suhrkamp, 1974.

ADORNO, Theodor W.; HORKHEIMER, Max. Dialética do esclarecimento: fragmentos filosóficos. Rio de Janeiro: Jorge Zahar, 2006.

DUSSEL, Enrique. Hacia un Marx desconocido. Un comentário de los Manuscritos del 61-63. México: Siglo Veinteuno Editores, 1988.

DUSSEL, Enrique. El último Marx (1863-1882) y la liberación latino-americana. México: Siglo Veinteuno Editores, 1990.

HEGEL, G. W. F. Linhas fundamentais da filosofia do direito ou direito natural e ciência do Estado contemporâneo. Tradução: Paulo Meneses et alii. São Leopoldo, RS: Ed. Unisinos, 2010.

HORKHEIMER. Teoria tradicional e teoria crítica. São Paulo: Brasil, 1975.

\begin{tabular}{|c|c|c|c|c|}
\hline Q Revista Dialectus & Ano 5 & n. 12 & Janeiro - Julho 2018 & p. $439-461$ \\
\hline
\end{tabular}


FLICKINGER, Hans-Georg. O potencial crítico da filosofia do direito. In: Revista Veritas, Porto Alegre, v. 49, n. 1, março, 2004, pp. 31-47.

MARX, Karl. Crítica da filosofia do direito de Hegel. São Paulo: Boitempo, 2005.

MARX, Karl. A questão judaica. In: Manuscritos econômico-filosóficos. Lisboa: Edições 70, 1964.

MARX, Karl. Manuscritos econômico-filosóficos. Lisboa: Edições 70, 1964.

MARX, Karl. O capital: crítica da economia política. v. 1, Rio de Janeiro: Bertrand Brasil, 1988.

NOBRE, Marcos (Org.) Curso livre de teoria crítica. Campinas, SP: Papirus, 2008.

MAAR, Wolfgang Leo. Materialismo e primado do objeto em Adorno. In: Revista Trans/Form/Ação, vol. 29, n. 2, pp. 133-154, 2006.

SCHÜTZ, R. Sensibilidade emancipatória: Schelling, Feuerbach e Marx à contrapelo da tradição. In: Prof. Dr. Eduardo Chagas; Deyve Redyson; Márcio de Paula. (Org.). Homem e Natureza em Ludwig Feuerbach. Fortaleza: Edições UFC, 2009, p. 171-212.

SCHÜTZ, R. Refúgio de liberdade: sobre a concepção de filosofia em Theodor Adorno.

In: Revista Veritas. Porto Alegre, v. 57, p. 32-52, 2012.

\begin{tabular}{|c|c|c|c|c|}
\hline Rovista Dialectus & Ano 5 & n. 12 & Janeiro - Julho 2018 & p. $439-461$ \\
\hline
\end{tabular}

